\title{
HUMANISTAS CONTRA ESCOLÁSTICOS. REPASO DE UN CAPITULO DE LA CORRESPONDENCIA DE VIVES Y ERASMO
}

\author{
EnRique González González
}

Facultad de Filosofia Y Ietras Universidad Nacional Autónoma de MÉxico

Cualquier aficionado al estudio de la primera mitad del siglo xvi europeo tiene al menos una idea de la importancia del epistolario de Erasmo en el marco de la historia intelectual de la época. Hoy conocemos unas 3141 cartas a y de Erasmo. ${ }^{1}$ Aquel escritor roterdamés (1467?-1536) estuvo en contacto epistolar con más de 2000 corresponsales de toda la Europa cristiano-latina. Se escribió con emperadores, reyes, altos funcionarios de estado o simples secretarios; con papas o jerarcas eclesiásticos, a la par que con los líderes de la Reforma; con las más destacadas figuras del humanismo en Italia y en el resto de Europa y con el más modesto profesor de provincia; con encumbrados mercaderes y con personas de ningún reỉieve cultural o social. Apenas hubo alguien en aquella sociedad de analfabetas que supiera escribir un poco de latín y simpatizara con los nuevos métodos de estudio o con una espiritualidad menos apegada a las fórmulas y más ligada al sentimiento y la interioridad, que no quiera escribir al famoso erudito, con esperanzas de una contestación para presumirla a sus amigos.

Tan inusitada actividad epistolar sólo se explica si tenemos en cuenta que aquel diminuto e infatigable holandés había sido puesto al frente de los humanistas que luchaban por extender los métodos y preocupaciones del humanismo italiano al norte de los Alpes. Extender, no sólo en su sentido geográfico sino también en el de llevar dichos métodos a nuevos campos, como el de la reforma de la teología. De ahí que al

1 Ningún estudio significativo acerca de Erasmo se ha escrito en español. En traducciones, pueden consultarse el Erasmo, de J. C. Huizinga, Buenos Aires, Emecé, 1946 y ss. El Erasmo de E. L. Halkin, aunque demasiado general, es claro y confiable. Dedicado a un asunto particular, pero rico en consideraciones generales, el clásico de M. Bataillon, Erasmo y España, México-Buenos Aires, F.C.E., 1950 y ss. L. Riber editó un volumen de Obras escogidas, Madrid, Aguilar, 1956, del que excluye los tratados teológicos más importantes, pero presenta una buena selección epistolar. 
humanismo transalpino se le designe comúnmente como nórdico, cristiano o, también, erasmista.

Rasgo central común al humanismo de ambos lados de los Alpes fue su lucha contra la escolástica, quiero decir, contra el tipo de saber y de enseñanza de las universidades medievales. $O$ más precisamente: contra el instrumentum que estaba a la base de la concepción medieval de las artes y las disciplinas. No se trató pues, como suele afirmarse, de que los humanistas, cansados de la formación filosófica de la facultad universitaria de artes, hubieran propuesto como alternativa una enseñanza de tipo estrictamente literario y retórico. $\mathrm{Ni}$ de que la reforma de las disciplinas que querían estos novatores no hubiese ido más allá del terreno "pedagógico". Lo que sucedió fue que, enfrentados humanistas y escolásticos en torno al problema del mejor método para la adquisición y la transmisión del saber, aquel saber seguía siendo, para unos y otros, de carácter escolar y libresco, de modo que su punto de referencia obligado era la universidad y, dentro de ella, la cuestión del papel instrumental de las llamadas artes liberales. Trataré de explicarme.

La facultad de artes, como se sabe, era la base de la enseñanza universitaria medieval. Sólo el que había cumplido con sus estudios podía ingresar a las facultades superiores de medicina, derecho civil o derecho canónico y teología. Se la llamaba así porque en última instancia se dedicaba al estudio de lo que en las escuelas públicas romanas se conoció como artes liberales, es decir, por un lado, las artes del lenguaje o artes sermocinales o, simplemente, trivium: gramática, dialéctica (es decir, lógica) y retórica: asimismo, las artes matemáticas o quadrivium: aritmética, geometría, astronomía y música. $Y$ aunque tal clasificación formal del saber escolar (es decir, de las disciplinas) nunca fue cuestionada en cuanto tal, en la práctica había sido considerablemente enriquecida, y aun rebasaba, con los aportes del corpus aristotélico y de la ciencia y filosofía árabes.

Ahora bien, si las artes matemáticas no presentaban mayor problema en cuanto a la determinación de sus respectivos campos, las artes sermocinales, por el contrario, nunca pudieron deslindar sin equívocos el terreno de la gramática, de la retórica y de la dialéctica. Es más, si algo caracterizó a la filosofía medieval es la gran atención que concedía al estudio de la lógica, al grado de que ésta fue convertida, no sólo en un instrumentum de todo el restante saber, sino en un fin en sí misma, por lo que a partir del siglo xiII invadió, por así decir, el terreno de la gramática, descartó el estudio de la retórica, y llevó sus métodos a los distintos campos de la filosofía natural y moral, así como del derecho, medicina y teología. Nada tiene de raro entonces que, en la facultad de artes, los dos primeros años, de tres que duraban sus cursos, se dedicaran 
de modo exclusivo al estudio de la lógica, y el tercero, a las restantes ramas de la filosofía, mismas que eran abordadas desde una perspectiva lógica.

Y puesto que la lógica era el instrumento del restante saber en la universidad medieval, el disgusto de los humanistas por la escolástica se manifestó ante todo como un repudio del papel primordial de la lógica en el interior de las artes sermocinales. Los humanistas, herederos más directos de la tradición literaria romana, reivindicarán para la retórica la primacía que los escolásticos habían concedido a la dialéctica, y pugnarán por una lógica subsidiaria del arte de la elocuencia.

Para mejor entender el sentido de la polémica, ${ }^{2}$ digamos que en la facultad medieval de artes el curso de lógica se daba a tres niveles, y en cada uno de ellos esta disciplina era estudiada a través de lecciones teóricas y de ejercicios prácticos o disputas. El primer nivel se ocupaba del estudio de la llamada ars vetus, que abarcaba el análisis lógico de los predicables, de los nombres y de las proposiciones. Para ello se valían, respectivamente, de la Isagoge de Porfirio, y de las Categorias y De interpretatione de Aristóteles. El nombre de vetus procedía del hecho de que sólo los mencionados títulos del Organon aristotélico estuvieron a disposición de los estudiosos medievales con anterioridad al siglo xur. A partir de entonces, los restantes escritos lógicos del Estagirita fueron traducidos al latín e incorporados al currículum escolar con el título de Logica nova, y constituían un segundo nivel en el estudio de la lógica. Estos libros consistian en: los Analytica priora y posteriora, que se dedicaban al estudio de los silogismos categóricos e hipotéticos; los Topica, para los lugares comunes; y, finalmente, los Sophistici elenchi, que examinaban las falacias.

Por último, a partir del siglo xir, y en concordancia con el auge de los estudios lógicos, empezaron a añadirse a los resúmenes escolares de los libros aristotélicos -llamados summulae - unos trataditos de nuevo cuño, dedicados a un análisis más a fondo de los elementos (términos) de una proposición, es decir, se ocupaban del análisis de las propiedades de los términos. Estos nuevos tratados, debido a su brevedad, recibieron el nombre genérico de parva logicalia.

La más famosa de estas summulae, debida al menos en su mayor parte al portugués Pedro Hispano, se convirtió en texto corriente de lógica desde mediados del siglo xIII hasta mediados del xvi. Estaba dividida en once tratados. Los seis primeros se ocupaban de la logica vetus

2 Para la lógica medieval, véase, en traducción española, la parte correspondiente en I. M. Bochenski, Historia de la lógica formal, Madrid, Gredos, 1966, con excelente bibliografía. Un panorama de la semiótica medieval en la Introducción de M. Beuchot a La filosofía del lenguaje en la Edad Media, México, UNAM, 1981, también con bibliografía. 
y de la nova, reformulando sus materiales como sigue: en el primero se examinaba la proposición, así categórica como hipotética; en el segundo, los predicables; en el tercero, las categorías; en el cuarto, los silogismos; quinto, los tópicos o lugares comunes; sexto, las falacias. A partir del séptimo tratado, hacía su aparición la logica modernorum, y generalmente comprendía los siguientes tratados (parva logicalia):

Séptimo: De la propiedad de los términos;

Octavo: De las voces sincategoremáticas;

Noveno: De las obligaciones;

Décimo: De los insolubles;

Undécimo: De las consecuencias.

Esta logica modernorum constituyó un fermento que llevó a la reformulación de los materiales tratados por Aristóteles. Quiero con esto decir que, a partir de su desarrollo como disciplina autónoma, "englobó", en función de su propio método o vía - la vía nominalista o terminista- los escritos lógicos de su maestro. Así, lo que en tales cursos se leia no era una exposición crítica y rigurosa del pensamiento de Aristóteles, sino que, de sus escritos, se tomaban materiales para una nueva construcción. Lógica aristotélica sí; pero no la de Aristóteles, sino la dı ellos, lógica escolástica. Esta disciplina nueva se convirtió en instrumentum para la reformulación de los escritos no lógicos de Aristóteles y del resto de ciencias de la enciclopedia medieval, incluia la teología.

La peculiaridad de la filosofía medieval es, en buena medida, una consecuencia de este original desarrollo de la lógica, que recibió el nom. bre de terminista por su énfasis en los términos del lenguaje, y que tenía punto de partida del lenguaje ordinario, al cual el uso había impuesto un significado. Sin embargo, esta primera instancia de significación importaba poco al lógico, preocupado por la estructura formal de las proposiciones de tal lenguaje. Para esto tenía que recurrir a un metalenguaje, a una segunda impositio. El nuevo lenguaje que de aquí resultaba, ahora de tipo lógico, permitía prescribir las condiciones o reglas para cualquier inferencia válida, y discernir entre éstas y las inválidas, especialmente en el caso de los sofismas, que eran resueltos mediante la aplicación de principios generales válidamente inferidos, que permitieran debelar cada caso particular.

En aquellas escuelas, el profesor tenía la misión de leer el libro de un autor con rango de autoridad, y de comentar las proposiciones en él contenidas a fin de despejar dudas, posibles ambigüedades o malinterpretaciones del texto que los estudiantes oian. Y para que el asunto quedara firmemente grabado en la mente del auditorio, el lector pro- 
ponía a sus oyentes una serie de dudas o questiones que estos debían despejar mediante ejercicios de disputa o disputationes. Las questiones a disputar solían preesntarse bajo la forma disyuntiva utrum...ut (o esto...o aquello), y eran suscitadas por el propio texto o a veces el profesor las tomaba de cualquier palabra del mismo, así no tuvieran nada que ver con el contexto.

Lo importante de estas questiones disputandae es que, si en algún momento tuvieron la finalidad práctica de aclarar un asunto concreto, conforme la dialéctica medieval fue desarrollándose, dicho ejercicio pasó a tener la finalidad didáctica de proponer la discusión de cuestiones abstractas en un contexto concreto. ${ }^{3}$ Por la misma razón, aquellas cues. tiones, casi siempre capciosas, conscientemente falaces, sofisticas, se volvieron progresivamente rebuscadas, sofisticadas. Pero no para engañar al alumno, sino para motivarlo a encontrar, mediante un análisis semántico de aquel enunciado, el punto donde es encontraba la inconsistencia, es decir, la falsedad lógica del mismo. Entonces, el mejor profesor vino a ser aquél que tenía mayor agudeza para proponer tales acertijos. Lax, el maestro de lógica de Vives, estaba orgulloso de ser considerado "el príncipe de los sofistas parisienses". Los humanistas, en su momento, no desaprovecharon la ocasión de dar a sofista su tradicional sentido peyorativo y rechazaron en bloque toda aquella lógica, a la que consideraron mera sofisteria.

Aquellos ejercicios de disputación acabaron siendo tan importantes que vino a dedicarse a ellos mayor tiempo que el empleado en las lecciones de los autores. Tales ejercicios estaban minuciosamente reglamentados y, cuando eran públicos, constituían verdaderos espectáculos en los que el auditorio podía participar, circunstancia que con frecuencia daba pie a verdaderas batallas campales. Antes de cada grado académico, el aspirante debía disputar públicamente de una determinada manera. Y tal ejercicio, lejos de desaparecer en las facultades superiores, era fundamental para la carrera de teología. De ahí la fama de rijosos y quisquillosos que los teólogos escolásticos tenían. Vives recordaba que su maestro Dullaert, pequeño, pálido y macilento, a la hora de disputar se llenaba de vida y parecía cobrar estatura. ${ }^{4}$

Para asomarnos ahora a la materia de aquellas polémicas, digamos que el término humanista, nacido en Italia hacia el siglo xv, empezó a ser aplicado al profesor de humanidades para distinguirlo del profesor universitario de artes o artista, el cual, según veíamos, centraba su ense-

3 Gucrlac, R. (ed. y trad.) Juan Luis Vives Against the Pseudodialectitians. Synthese Historical Library, vol. 18, Reidel, Dordrecht (Holanda), 1979, p. 4.

4 Compárese el profesor que aparece al fin del diálogo Schola con la descripción de Dullaert en la Vita que Vives le escribió. 
ñanza en el estudio de la dialéctica, disciplina que había acabado por ahogar a las dos artes sermocinales restantes: la gramática y la retórica. Los humanistas, disgustados por el predominio de la dialéctica, predominio al que achacaban buena parte de los males de su tiempo - al menos en lo tocante a lo que ellos llamaban "postración de los estudios"- empezaron a reivindicar el estudio de la gramática; pero gramática en el sentido en que hoy hablamos de literatura, y aun en un sentido más amplio, pues a la literatura pertenecían no únicamente la poesía y el teatro (la novela apenas si existía), sino toda la prosa, así se ocupara de cuestiones históricas, jurídicas, filosóficas o incluso de arquitectura y agricultura. Por tal motivo, cuando la polémica entre ambos bandos estalló, los humanistas declaraban su desprecio por los escolásticos tildándolos de sofistas; éstos, en contrapartida, decían que los humanistas no pasaban de gramáticos, calificativo que resultaba peyorativo porque el profesor de primeras letras (que no era mucho más que esto lo que se enseñaba en las escuelas de gramática durante la Edad Media) estaba situado en el lugar más bajo del escalafón académico.

Para este proceso de revaloración del papel del gramático y de su tipo de estudios fue una pieza clave el concepto de studia humanitatis, gracias al cual fue posible, sin salir del campo de las artes sermocinales, dar la pelea a la lógica terminista en su propio terreno, y poner el énfasis en las artes liberales como un conjunto, no como disciplinas susceptibles de ser reducidas a la dialéctica, y encaminar el estudio de éstas hacia la formación del hombre entendido como un ciudadano elocuente.

Sabido es que, para la tradición grecorromana, cuya heredera fue la Edad Media, existía la distinción entre artes liberales o propias del hombre libre, que se agrupaban en artes sermocinales y artes del número, y las artes serviles o bajas, centradas en la destreza manual. Ahora bien, de entre las artes dignas del hombre libre, es decir, del hombre a secas, las artes sermocinales eran tenidas por más humanas (humaniores) que las otras, pues se centraban en la calidad humana por excelencia: el habla. De este modo, los studia humanitatis eran aquellos que enseñaban la elocuencia. Pero la eficacia del lenguaje no se desplegaba individualmente sino se aspiraba a alcanzarla en la sociedad de los hombres. Y como esta sociedad se desenvolvía en medio de instituciones legales y políticas, éstas sólo podían mantenerse —según las creencias político-morales de la época- si constituían asociaciones de hombres buenos. La verdadera elocuencia, pues, no podía darse al margen de la virtud. De ahí que el ideal romano de educación se cifrara en la máxima: vir bonus dicendi peritus: hombre bueno experto en el habla. Y en base a dicha máxima, Quintiliano escribió el gran tratado pedagógico 
de Roma, que tanta boga tendría entre los humanistas, la Institutio oratoria.

Así pues, la tradición literaria romana, de la que Quintiliano había sido el pedagogo minucioso - Gicerón era el modelo de elocuencia, no el teórico de aquella enciclopedia de disciplinas - se abría como una alternativa orgánica para muchos de aquellos estudiosos de los siglos xv y xvı, desempeñados de la enseñanza impartida en las escuelas, pero que se resistían a recurrir al solitario refugio de la mística, dado que su vida giraba en torno a los asuntos públicos y privados de la ciudad. Entonces se dieron apasionadamente a los studia humanitatis, que eran, sí, un método de enseñanza, una doctrina, pero que por ello mismo, eran proclamados una virtud, pues sus partidarios aseguraban que este tipo de estudio hacía a quien lo adoptaba un verdadero hombre, es decir, un ciudadano. Podemos resumir diciendo que durante los siglos xv y xvı, era aquel individuo formado en los studia humanitatis, y convencido de las virtudes morales de aquellos métodos para la formación óptima del hombre.

Para los humanistas, el saber de los escolásticos podía resultar lógicamente impecable, todos sus pasos ser consequentiae estrictamente formales de las operaciones anteriores, pero, por lo mismo, era incapaz de salir de sus propias reglas. De ahí que acabó por disgustar profundamente a aquellas personas ocupadas en menesteres mundanos como la política, los negocios, las artes mecánicas, dado que no aportaba nada a sus necesidades de saber práctico. De ahí que se dieran a la búsqueda de un método capaz de sistematizar el mundo de los conocimientos optativos, cuestionables, de los juicios inciertos, es decir, capaz de englobar las masas de nueva información que estaban llegando con el comercio en alta escala; las de los talleres donde se cultivaban las artes mecánicas "superiores" como pintura, escultura, arquitectura, que habían empezado a formular teóricamente los viejos postulados empíricos que constituían la tradición del gremio, como en el caso de la teoría de la perspectiva; ${ }^{5}$ finalmente, un saber que ayudara a secretarios y administradores públicos en sus deliberaciones, que rara vez tenían el carácter de deducciones necesarias.

Gentes como Petrarca, conocedores de la historia y de la literatura clásica, pusieron de relieve el contraste entre un saber y el otro. Entonces se convirtió en tópico la yuxtaposición de la dialéctica de los modernos (es decir, los escolásticos), verbal, rijosa, huera y obscura, con la sabiduria de los antiguos, elocuente, serena, enjundiosa y clara. Los par-

5 Véase, Panofsky, E., Renacimiento y renacimientos en el arte occidental, Madrid, Alianza Universidad, pp. 186-191. 
tidarios de la "claridad de los antiguos" se dieron apasionadamente a la recuperación de los monumentos de aquel pasado. $\mathrm{Y}$ no por razones esteticistas, como sigue siendo común decir, ni por una comodina sustitución de las arideces filosóficas por la exquisitez de las letras -asunto en el que hay que insistir-, ni por refugiarse en un pasado fantástico de los afanes del presente, o por negarse a reconocer conocimientos nuevos, distintos de la antigüedad. Los humanistas hablaban de un re-nacimiento, es decir, de una revivificación - no de una repetición- del saber de los antiguos. $\mathrm{Y}$ si aquéllos se opusieron a las "novedades inauditas" de los escolásticos, fue por su firme convicción de que los modernos no habían aportado ningún conocimiento nuevo ni viejo, sino que sólo depravaron los genuinos métodos de las artes, por haberse aferrado a la autoridad de un Aristóteles que de Aristóteles sólo tenía el nombre, y que lo que las escuelas habían creído que era un avance, no fue sino dar pasos en círculo. En suma, al rechazar la escolástica no creían dar un no a la filosofía, sino a la pseudo-filosofía. Vives no escribió contra la dialéctica, sino contra los pseudo-dialécticos.

Para no entrar aquí en mayores detalles, podríamos resumir el caso diciendo que, mientras el método de los escolásticos era deductivo, el de los humanistas, en cambio, histórico analítico. Para los primeros, bastaba un cierto grado de pericia en el arte de la dialéctica que permitiera deducir la verdad o la falsedad de cualquier enunciado para poder discernir acerca de cuestiones de filosofía natural y hasta de teología. Para los segundos, sin un estudio profundo de la historia, de las artes liberales y de los autores que tratan de todas esas materias, no hay conocimiento positivo alguno sino mera especulación acerca de productos calenturientos de la mente.

Significativamente, del mismo modo como Abelardo partiera del De differentiis topicis de Boecio para asimilar la teoría de los silogismos a la más amplia de las consequentiae, ${ }^{6}$ los humanistas partieron del mismo libro de Boecio para sistematizar las técnicas de argumentación no silogísticas, en particular la inventio y el juicio, con el fin de presentarlas como del mismo o aun mayor valor que el silogismo, cuya teoría solía presentarse en los manuales de lógica humanística sólo una vez que se había presentado y desarrollado la teoría de los tópicos. ${ }^{7} \mathrm{Al}$ propio tiempo, los humanistas retomaron de los mismos autores latinos que los dialécticos medievales el esquema de las artes liberales, que incluía la triada de las sermocinales, cuyo cultivo rebautizaron, sin duda para darle nuevo

6 Moody, E. A., Truth and Consequence in Medieval Logic, Amsterdam, 1933 (Reimpr. por Greenwood Press, 1976), pp. 9-10.

7 Jardine, L., "Lorenzo Valla and the Intellectual Origins of Humanistic Dialectic". en Journal of the History of Philosophy, 15 (1977), p. 145. 
énfasıs, cumo studia humanitatis. Ahí volcaron sus inquietudes históricas, sociales, metodológicas, en una palabra, su espíritu crítico.

Pero tal teoría lógica, desarrollada especialmente por Valla y Agrícola, habría sido imposible sin una previa revaloración de la gramática. Se partió de la distinción romana entre el litterator o profesor de primeras letras y el grammaticus, que instruía en el manejo del idioma y en la lectura y comentario de los principales autores: poetas, dramaturgos, oradores e historiadores. En la Edad Media, en cambio, el título de gramático correspondió simplemente al del profesor de primeras letras; dicho mentor, representante ínfimo de la jerarquia docente era seguido por el dialéctico o artista y, en la cima, el teólogo. Y como cada nueva etapa del currículum era considerada una superación de la anterior, además de que recibía mejor paga, se tenía como vanidad volver a las esferas inferiores. De esta manera, sin que los escolásticos fueran necesariamente enemigos de las letras, daban por sentado que, pasada la escuela gramatical, la poesía estaba bien para que los estudiantes adornaran con ellas las guardas de los libros de dialéctica, y para que la cita de algún poeta $\mathbf{u}$ orador adornara una epístola dedicatoria. Pero nada más. Lo que generalmente era mal visto era que se quemaran etapas, de ahí que la costumbre de los dialécticos de hacer silogismos con asuntos teológicos llevara a constantes fricciones a la facultad de artes con la teología.

Los humanistas en cambio, decidieron devolver al nombre de gramá. tico el perdido prestigio. En adelante, un gramático sería lo que hoy llamamos un hombre letrado. El hecho no molestó en un principio a los maestros de artes, que asistieron con indiferencia a la readaptación de los viejos manuales de latín, así como a la proliferación de profesores italianos o italianizantes que, al margen de las cátedras oficiales, se dieron a la lectura de autores latinos y aun griegos: allá los gramáticos. El problema empezó cuando éstos, por sobre declararse orgullosos de su infima profesión, empezaron a inmiscuirse en cuestiones juridicas y teológicas.

Una notable e inquietante audacia de ellos fue protagonizada por Budé, el futuro amigo de Vives y Erasmo, cuando dio a la prensa, en 1508, unas Annotationes a las Pandectas: en este caso, se corrigió y explicó el texto jurídico, no con base en Acurcio y en los glossatores y postglossatores, que fueron tildados de ignorantes, sino a partir de los propios autores griegos y romanos, cuyas lenguas Budé conocía a fondo. Dicho libro significaba tanto como cuestionar la base misma de la enseñanza de derecho civil en las universidades.

Lorenzo Valla (1407-1577) no sólo había sentado las bases para la fundamentación de la lógica humanística; sin más apoyo que el de su eru- 
dición filosófica, este "gramático" se dio al examen comparado de los textos griego y latino de la Biblia. En otra ocasión, aplicando la crítica textual, demostró que la Donación de Constantino, el famoso documento en que se fundaba legalmente la posesión papal de los Estados Pontificios, no era sino un escrito apócrifo, lleno de anacronismos. El español Nebrija, por su parte, no se limitó a las famosas gramáticas latina y castellana: diciéndose discípulo de Valla, emprendió el comentario a 50 lugares de la Biblia, manuscrito que le decomisara el Inquisidor Deza. ${ }^{8}$ Erasmo, que en 1506 preparó la edición príncipe de las Anotaciones bíblicas de Valla, fue el primero en proponer de manera expresa y sistemática el aprovechamiento de los métodos críticos del humanismo italiano para la reforma de la teología cristiana. Ésta, que durante los primeros siglos del cristianismo apenas había sido otra cosa que exégesis de los textos bíblicos, en la universidad medieval se convierte en una disciplina "profesional", sistematizada mediante series de questiones a disputar, con la consecuencia del práctico abandono del estudio de la Escritura. John Mair, el más famoso profesor de teología en París hacia 1510, afirmaba que la Biblia era la parte más fácil de su disciplina, ${ }^{9}$ sintoma evidente del poco interés que despertaba; apenas mayor del que existía por otros escritores, eclesiásticos o no, anteriores al desarrollo de la escuela medieval.

Aquel holandés de voz aflautada y salud quebradiza, pero de gran elocuencia y capacidad de trabajo, con su febril actividad literaria y editorial pronto invadió aquel continente con escritos que reproponían el ideal petrarquista de la docta pietas: una religiosidad que no estuviese reñida con la erudición y con el gusto por las letras humanas. Propone nuevos métodos de estudio en concordancia con semejantes ideas: la formación de los jóvenes debía partir del conocimiento de las lenguas, que eran la llave para el conocimiento de los autores y del saber en ellos guardado. El adolescente formado de esta manera no debía ser disputador sino elocuente: en vez de clamar, debía declamar. Siendo la elocuencia el arte de mover los afectos humanos, su objetivo, más que ven. cer, era convencer, pues el fin del estudio no era su simple desarrollo dentro de los claustros universitarios, sino la educación del pueblo. En las cartas que aquí traeremos a cuento, Erasmo insistirá en que con los nuevos métodos no sólo los estudios se verian beneficiados sino también el país. Cuando en 1525 Vives servía a Enrique VIII en Inglaterra, propuso al monarca la educación de todos los niños del reino, tanto en religión, para la elevación de sus mentes y de sus costumbres, como en

8 Bataillon, op. cit., p. 39.

- A. Renaudet, Préreforme et humanisme a Paris pendant les guerres d'Italie, reimpreso en Ginebra, Slatkine, 1982, p. 470. 
las letras, a fin de que aprendieran las leyes y otros conocimientos útiles para la vida. Una vez "alfabetizadas" estas personas, su formación literaria podría consolidarse a través de sermones - diríamos hoy, conferencias- y de ediciones de libros, en lengua vulgar, que trataran de temas instructivos y útiles. Consecuentemente, para una concepción del saber tan diferente de la escolástica, aquella lógica de disputas acérrimas dejaba de ser la base, el instrumentum de todo saber. La lógica que los humanistas se proponen desarrollar no insistirá tanto en demostrar como en mostrar. Una lógica puesta al servicio de la elocuencia sería capaz de educar, y no sólo a los estudiantes sino a la sociedad entera.

Por último, y éste fue su mayor atrevimiento, en febrero de 1516 Erasmo lanzaba una edición en griego y latín del Nuevo Testamento donde ofrecía una nueva traducción del texto griego, distinta de la canónica, redactada por San Jerónimo, Formando parte de lo anterior aparecía un gran aparato crítico, a modo de notas al pie, con noticia de las variantes, de los problemas que ciertos pasajes suscitaban y de las interpretaciones que de ellos habian hecho los distintos escritores eclesiásticos, del motivo por el que Erasmo había traducido cualquier párrafo de manera distinta a San Jerónimo, etc. Significativamente, al comienzo del Evangelio de San Juan, donde la Vulgata decía que en el principio era el Verbo, Erasmo interpreta la palabra griega logos (tan emparentada con la de lógica) por sermo: In principio erat Sermo: en el origen estaba la elocuencia divina que creara al mundo; esta misma elocuencia podría transformar al hombre con sólo que se dejara estremecer por su contacto creador. La verdadera teología, escribió en el prólogo, consiste en dejarnos transformar por la divina elocuencia, gracias a la vivencia inmediata de la palabra de Dios. $Y$ esto valía igual para el príncipe que para el labriego, que un día cantaría la palabra de Dios mientras tiraba del arado.

Semejantes "despropósitos" difícilmente hallarian buen eco en los medios tradicionalistas. Pero lo que más indignante parecía, era que aquel amasijo de asuntos "de gramática" se presentara a sí mismo como el Novum Instrumentum, como el verdadero método para iniciarse en la auténtica teología. A partir de este momento se hace casi imposible no tomar partido por o contra Erasmo. Los defensores de la vieja teología y del viejo estilo de enseñanza, casi siempre monjes franciscanos o dominicanos, se atrincheraron en sus conventos y detrás de la influencia que les daban las cátedras universitarias: Erasmo desconocía la teología dogmática, ergo era enemigo del dogma. El surgimiento casi simultáneo de Lutero y del partido de la Reforma exacerbó más los ánimos. Para estos teólogos, Erasmo y Lutero eran la misma herejía, o punto menos.

También los defensores de los nuevos modos de enseñanza -lutera- 
nos o no- se ven forzados a cerrar filas, y los ojos de todos se vuelven a Erasmo como a su caudillo natural. De este modo el teólogo holandés, ya famoso por sus escritos, se ve más acosado que nunca por corresponsales de todas partes en busca de ayuda $\mathbf{u}$ ofreciéndola; llueven insultos, felicitaciones, promesas, sugerencias, chismes, dádivas, consultas. $\mathrm{Y}$ en medio de todos, él se defiende, ataca, hace todo lo posible por sostener a su partido. Entonces descubre la importancia que todo aquel material epistolar podría revestir como arma de lucha, y desde fines de 1516 hasta su muerte se lanza a la publicación casi anual de lo más destacado de las cartas que enviaba y recibła, logrando con ello un éxito fulgurante, tanto de "librería" como de propaganda.10

Organizadas al calor de las polémicas del momento, estas cartas son un testimonio único del precio que los humanistas del siglo xvi tuvieron que pagar para hacer valer sus ideas en un medio doctrinal e institucional dominado por profesores hostiles a toda novedad. Constituyen también material de primera mano para seguir la pista de personajes o de acontecimientos que de otra manera ignoraríamos o nos resultarían sumamente borrosos. Ahí tenemos, por ejemplo, una verdadera bitácora de las relaciones entre el roterdamés y la otra gran figura del humanismo europeo, Guillaume Budé (1468-1540). Ambos se admiran y se buscan; pero los respectivos temperamentos y la propia vanidad de quienes se saben estrellas, convierten la relación en un repertorio de malentendidos, pullas y suspicacias. Sin embargo, conscientes de que los tiempos no están para que dos humanistas de tanto renombre se peleen y siembren división entre sus filas, hacen penosos esfuerzos por evitar una franca ruptura. El valenciano Vives, que más de una vez mediara entre ambos humanistas tratando de disipar irritaciones, nos aparece aquí no nada más como el discípulo ferviente, sino como el colaborador decidido, cuyas recomendaciones suelen ser atendidas por Erasmo al pie de la letra, especialmente cuando se trata de asuntos españoles. ${ }^{11}$

Sobra decir que para un verdadero disfrute y aprovechamiento de material tan vivo como aquel epistolario, se hacia indispensable su reorganización: datación, esclarecimiento de lugares oscuros, de alusiones veladas a las que en tantas ocasiones era indispensable recurrir; noticias sobre los corresponsales o personas aludidas. A esta tarea se dieron los esposos Allen, ${ }^{12}$ partiendo de los intentos anteriores de clasificación y

10 Para las ediciones del epistolario erasmiano consúltese el vol. 1, Ap. VII, de la edición de Allen (ver No 12).

11 Una relación detallada de la colaboración entre ambos humanistas, en el Erasmo y España, passim, pero en especial los capitulos 3 y 5 .

12 P. S. Allen, H. M. Allen y H. W. Garrod, Opus epistolarum Des. Erasmi Roterodami, Oxford, Clarendon Press, 1906-41, 11 vols. e índice. Aquí citaré "Allen" y el núm. de la epistola. 
de otros estudios particulares ya existentes. No únicamente se valieron del material impreso, cotejando los textos de las numerosas ediciones; además, barrieron bibliotecas y archivos europeos en busca de la última traza de una carta manuscrita de o a Eraasmo. Parte de esos originales, por cierto, fue destruida durante los bombardeos de la primera o segunda guerras. La sola preparación y edición de aquello tomó de 1906 a 1958, y el resultado fueron once volúmenes, más el índice, donde las cartas aparecen con todas sus variantes y con la más impresionante profusión de notas, que son, al mismo tiempo, modelos de claridad y concisión.

Con ser el resultado tan rico, no podía menos que presentar aquí y allá asuntos no cabalmente aclarados, conclusiones tal vez equivocadas; pero, de cualquier modo, susceptibles de discusión. Tal es el caso de tres de las cartas del epistolario de Vives y Erasmo, las editadas con los números 1104, 1108 y 1111, cuyas conclusiones han despertado cierta perplejidad y propiciado confusión. Un replanteamiento de los problemas suscitados por ellas, a la vez que nos permitiría precisar algunos puntos en la cronología de la vida y escritos de Vives, nos brinda la ocasión de echar un vistazo al ambiente en el que aquellas polémicas terían lugar, al tipo de relación que se establece entre Erasmo y Vives durante los primeros años de contacto $\mathrm{y}$, por último, a la clase de dificultades que la investigación actual debe sortear si quiere poner algo de orden en aquellos problemáticos y lejanos documentos.

Antes de pasar al estudio de las tres cartas indicadas, apuntemos algunos antecedentes. Vives y Erasmo se conocieron probablemente en 1516 en la corte de Bruselas, donde Carlos, de apenas 16 años, acaba de nombrarse rey de Castilla y Aragón y se prepara a viajar a esos dominios. Erasmo, protegido por los más importantes ministros del nuevo rey, es nombrado consejero a mediados de año, para lo cual su presencia es requerida en Bruselas. Su Novum Instrumentum apareció en febrero y ya se oye el disgusto de los teólogos de Colonia. ${ }^{13}$

Vives, ${ }^{14}$ unos 25 años más joven que el casi cincuentón holandés, había nacido en Valencia (1492/3), donde aprendió las primeras letras,

13 W. K. Ferguson, Erasmi opuscula, La Haya, Nijhoff, 1933, pp. 239-241.

14 Hay una traducción incompleta y no demasiado precisa de las Obras Completas, por L. Riber, Madrid, Aguilar, 1947-1948, 2 vols. Es clásico el estudio de Bonilla, Luis Vives y la filosofía del Renacimiento, Madrid, 1903; pero sus 80 años lo han envejecido. Más actualizado, el. Juan Luis Vives, de C. G. Noreña, La Haya, M. Nijhoff, 1970, trad. al español para Ediciones Paulinas, Madrid. 
para luego estudiar artes y al parecer algo de derecho en la universidad de su ciudad, recién fundada. Alrededor de 1509 pasa a París, donde reinicia los estudios de filosofía, bajo la dirección de "sofistas" como Lax y Dullaert y, si creemos el testimonio de Erasmo, ${ }^{15}$ llegó a ser de los primeros en aquellas disciplinas. Ligado a los Países Bajos desde 1512, cuando visita Brujas, ciudad donde tenía parientes, no abandona entonces sus estudios parisienses. En 1514, si no un poco antes, empieza a dar cursos no formales de retórica ${ }^{16}$ y a inclinarse por el humanismo, aunque sin reaccionar todavía contra los métodos escolásticos. Entonces también publica nueve o diez de sus primeros escritos, todos de gran brevedad.

Abandona de plano París hacia el otoño de 1514, quizás decepcionado por la mala paga de los estudiantes parisinos o por la falta de grandes perspectivas en aquel medio sobresaturado de "intelectuales". Había empezado a experimentar disgusto por las viejas disciplinas, a la par que un interés onmívoro por cuanto libro de autores clásicos venía a sus manos. Sin embargo, fuertemente entrenado en la lógica y filosofía escolásticas, no las cambiará fácilmente por "gramática": que no otra cosa eran los estudios humanísticos para el punto de vista escolástico. Decidido a cambiar su patria por Brujas en vista de la enemiga de la inquisición valenciana contra su familia de origen judeoconverso, a finales de 1514 su presencia aparece documentada en aquella ciudad flamenca. ${ }^{17}$ Este mismo año o a principios del siguiente, llegaría a la ciudad de Lovaina, probablemente para dirigir los estudios del joven noble brugense Jacques de la Potterie.

Una vez en Lovaina, entra pronto en contacto con el pequeño grupo local de humanistas, ganados desde tiempo atrás a la causa de Erasmo. Ahí asiste, en 1515, a la edición príncipe de la Dialéctica de Rodolfo Agrícola, primer alternativa concreta a la lógica de los escolásticos, libro que tanto ayudó a Vives a la hora de ajustar cuentas con la dialéctica "sofística" de París, y que acabó por sustituir como texto universitario a los manuales medievales a partir de 1530 . Gracias a estas nuevas influencias, a las que pronto se sumaría la del magisterio de Erasmo, el español pudo salir de su larga crisis intelectual ${ }^{18}$ y entrar de lleno en el campo del humanismo. Su carta Aduersus Pseudodialecticos es el acta 15 Ep. de Erasmo a Neuenahr, Allen, 1082.

16 Cfr. su Prelección al IV libro de la Retórica a Herenio que, como espero mostrar en mi tesis de grado, pertenece al periodo de París y no, como se afirma, al de Lovaina.

17 E. Van den Bussche menciona dos documentos brugenses de fines de 1514, donde Vives aparece, en su "Luis Vives. Notes biographiques". En Revue de la Flandre, T. VIII, 1876, pero no tengo aqué la noticia de la $\mathrm{p}$.

18 Cfr. In pseudodialecticos, en la edición de Mayáns de las Opera Omnia, Valencia, 1982-90, vol. III, p. 39. 
definitiva de ruptura con la escolástica. La gran obra de su edad madura, De disciplinis (1531), es ante todo una crítica penetrante y côn. conocimiento de causa de los métodos escolásticos y un esfuerzo para encontrar nuevas vías para el conocimiento y para la fundamentación de las ciencias.

También en Lovaina, trabó contacto con el canciller de la universidad; Adriano de Utrecht, quien además era preceptor del joven príncipe Carlos. Llamado Adriano a residir en la corte de manera permanente, posiblemente llevó consigo a Juan Luis; la insistencia con que éste menciona a dicho personaje - que habría de ser el papa Adriano VI- y la referencia a favores concretos recibidos, autorizan a suponer que él abrió para Vives la corte de Bruselas. ${ }^{19}$ Lo cierto es que en noviembre de 1516 tiene en ella un empleo. ${ }^{20}$ En octubre, él fue uno de los primeros en prevenir a Erasmo de que los teólogos de la universidad de Colonia estaban molestos por su Testamento.

El encuentro de Vives con Erasmo es determinante como ninguno en la vida del todavía joven humanista español, quien se impregna hasta la médula del ideario erasmiano. En adelante, lo llamará con los títulos de preceptor, maestro, padre, y se convierte.en uno de sus más ardientes colaboradores. En todos sus escritos posteriores es visible la huella de la influencia que Erasmo ejerciera sobre él durante aquellos primeros años de estrecha convivencia en Lovaina. $\mathrm{Y}$ no porque exista. un divorcio entre el antes y el después de Erasmo, sino porque el Vives que maduraba confusa y penosamente en París, ve de pronto en Erasmo el espejo, el paradigma que le permite descubrir su propia vocación humanística. El valenciano que se había cansado de buscar al vir sapiens ${ }^{21}$ entre sus profesores de París, ahora lo encontraba en la persona del sabio de Rotterdam. Aquel entusiasmo de 1516, que aquí también veremos aparecer, seguía vivo y sin reservas en 1522, en el prólogo a sus Comentarios a la Ciudad de Dios. Y a pesar de que años después el cada vez más agrio maestro enfriara su afecto por Vives, éste, aunque había proseguido su

19 En la edición definitiva del Christi Triumphus (1519), aparecida en los Opuscula varia, Lovaina, Martens hay dos referencias a Adriano como preceptor óptimo del príncipe Carlos (ff. r4vo. y sl); al fin del De vita at moribus eruditi, Opera, Bas, I, p. 524, declara haber escuchado las intervenciones públicas de Adriano cuando era canciller de Lovaina, y en su carta al propio Adriano VI, dice una vez haber sido escuchado por el deán de Lovaina, y dos veces, haber sido escuchado por el obispo de Tortosa Opera, II 934.

20 Cfr. el I.uis Vives de Bonilla, pp. 733-734, la carta que dirigen a Vives los jurados de Valencia, donde se dirigen a él como "in curia regia residenti eiusque curiali", y J. Ijsewijn, "J. L. Vives in 1512-1517", en Humanistica Lovaniensia, 26, 1977 , pp. 89-90, que llama la atención sobre el pasaje.

21 Diálogo Sapiens, para el que vale lo dicho en la n. 16, Vives, con Bérault y su maestro Lax recorren las distintas clases de artes en la Universidad de París, en busca del profesor sabio. Lo hallan, pero fuera de la ciudad y universidad, en un ermitaño. 
particular desarrollo intelectual, nunca abandonó el partido de Erasmo. Séncillamente, porque desde años atrás había pasado a ser el suyo propio.

Dos acontecimientos independientes propiciaron que aquel inicial en. cuentro de cortesanos — que algo tenía de exasperante para Erasmo, a causa de la exhuberancia "salutatoria" ${ }^{22}$ de Vives - ganara en profundidad: Cuando en julio de 1517 la corte deja Bruselas para dirigirse a España, el nuevo consejero Erasmo prefiere no acompañarla, de modo que le asignan la ciudad de Lovaina a fin de que desempeñe algún tipo de actividad académica. El cortesano Vives, por su parte, recibe un encargo notable: dirigir los estudios en la universidad de Lovaina de Guillermo de Croy, de 19 años, abad del monasterio de Afflighem, obispo de Cambrai, cardenal desde julio de 1517 y, desde fines del mismo año, arzobispo de Toledo, la diócesis con rentas más altas en toda la cristiandad, después de Roma. Este muchacho era sobrino del señor de Chièvres, gobernador del príncipe Carlos durante su minoría de edad y, hasta su muerte en 1521, verdadero poder detrás del trono. Sin hijos, este valido que tanta fama de rapaz dejaría en España, no tenía ojos más que para favorecer a su familia, particularmente al sobrino que ahora quedaba en manos de Vives.

Reencontrados pues en Lovaina, el español tendría tiempo de sobra para ser enseñado por Erasmo y ocasión de apoyarlo en las pugnas que pronto estallarían entre el maestro y la universidad. En efecto, en agosto del mismo año muere el rico humanista Jerónimo de Busleyden, quien lega un fondo para la creación de un colegio donde debían aplicarse los métodos de estudio propugnados por el humanismo, y deja a Erasmo como uno de los ejecutores de su voluntad. El nuevo instituto recibe el nombre de Colegio Busleidiano o Trilingüe, pues en él, a la manera del fundado por el cardenal Cisneros en Alcalá, se haría especial hincapié en el estudio de las tres lenguas "sagradas": hebreo, griego y latín.

Establecido el Trilingüe en Lovaina a fin de que los nuevos estudios dieran otros aires a aquella amodorrada universidad, pronto estallan las más acres disputas entre ambas instituciones. Reyertas que se vieron mezcladas con los crecientes ataques al inspirador de aquel colegio, por su Nuevo Testamento y por sospechas de que estuviese ligado con aquel monje recién rebelado en Wittemberg. Vives se encargó desde un principio de que el cardenal su discípulo, con todo el peso de su influencia, se pusiera inequívocamente del lado de Erasmo y del Trilingüe.

Sin embargo, la universidad podía esgrimir en su favor un argumento legal de enorme peso: los estatutos prohibian la enseñanza pública y privada a cualquier profesor no inscrito en una de las facultades. Celosa

22 Erasmo se queja con Moro, en marzo de 1517, de la lata que le dan en Bruselas los "salutatores" españoles, en especial Vives, ep. 545. 
de sus privilegios y recelosa de los nuevos estudios, la universidad estaba dispuesta a hacer valer sus reales frente a la institución intrusa. La polémica alcanza su punto álgido con el caso del profesor Guillermo Nessen, que llega a Lovaina en julio de 1519, con el propósito de enseñar gratis la Geografia de Pomponio Mela. La Universidad lo prohibe, con el disgusto de numerosos estudiantes, que llegaron al grado de asaltar de no che la casa del rector (el 29 de noviembre) y exigir, con amenazas, la autorización para las clases de Nessen. Encarcelan al profesor del Tri. lingüe Rutger Rescius por presunta participación, y todo el negocio es llevado con Consejo de Brabante. ${ }^{23}$ Pasan las influencias de ambos lados, y hay necesidad de llegar a un acuerdo por el que la universidad reconoce al Trilingüe el derecho a profesar sin exigir previa incorporación a los maestros (12 de marzo de 1520); a cambio de ello, el reglamento para admitir a los profesores independientes se vuelve más restrictivo, Vives había obtenido este derecho desde el 3 de marzo: Nessen, en cambio, opta por irse a Nuremberg y en julio ya se ha instalado en Francfurt. ${ }^{24}$

\section{III}

Me he referido a tres cartas del epistolario de Vives y Erasmo cuya datación en la edición de Allen me parece incorrecta y fuente de confusiones. En la primera en cuestión (Ep. 1108, Progresso Mihi), Vives relata a Erasmo los avatares de un viaje a París, de modo vívido y pormenorizado. Erasmo la publicó, sin fecha, en 1521. Ahora bien, conocemos dos cartas de Erasmo, al parecer más o menos contemporáneas entre sí, en las que hay referencia a reciente viaje del valenciano a París. La más extensa de ambas (Ep. 1111, Subtristem me) apareció en 1521, a renglón seguido de la de Vives, por lo que se entiende que es la contestación. En ella el maestro hace referencia a la negativa de la universidad de Lovaina a permitir a Nessen la realización de su curso de P. Mela. La circunstancia de que se aluda a hechos consumados en 1520 es puesta por Allen en relación con una referencia de la carta de Vives a la fiesta de la Trinidad, lo cual le permite datar ambas epístolas.

En efecto, Vives nos explica así su salida de París: dieque postquam illinc dicessi quinto, qui diuae Trinitate fuit sacer, perueni Brugas essedo vectus, postridie haec ad te scripsi (líns. 209-211). Texto que Riber y Jiménez Delgado coinciden en traducir, ${ }^{25}$ a mi juicio correctamente,

23 Cfr. Allen, Introd. a la ep. 1046.

24 Cfr. Allen, Introd. a la ep. 1057.

25 Riber, cit. en n. 8, II, 1688; y J. Jiménez Delgado en su traducción del Epistolario de Vives, Madrid, Ed. Nacional, 1978, p. 194. 
en el sentido de que Vives sale de París en día de la Santísima Trinidad, hace cinco días de viaje en carro hasta Brujas y a otro día escribe a su maestro. La fiesta de la Trinidad, de fecha variable pues depende de la de la pascua, cayó en 1520 en 3 de junio. Allen, que interpreta la anterior clave como si Vives hubiera llegado a Brujas el día de la Trinidad, data la carta el 4 de junio. De 1520, pues es el año de los sucesos mencionados en la respuesta de Erasmo la que debió escribir un poco después de recibida la carta de su alumno; por lo que no ve problema en suponerla del mismo mes de junio. El viaje de Vives a París, por tanto, se realizó en 1520, y sólo este par de cartas lo testimonian.

Todo quedara resuelto de no existir otra misiva de Erasmo (1104, Quid te felicius), más breve que la anterior, donde hay mención tanto de un viaje de Vives a París como del asunto Nessen. Publicada tardiamente en 1529, con data de 1519, Allen encuentra inaceptable la última fecha, vista la comunidad de asuntos con la ep. 1111 que, de acuerdo a sus conclusiones, era de junio de 1520. Opta, sin mucho convencimiento, por asignar a esta tercera en cuestión de fecha de "¿mayo? 1520" y la considera respuesta a otra carta de Vives, hoy perdida, en la que el español le relataba otro viaje a París, efectuado en 1519 , pero que eI holandés contestó tardíamente.

Una solución tan de compromiso, además de forzada, no resiste el análisis interno de los textos. En cambio, puede proponerse una solución menos tirante: que las tres cartas se refieren a un único viaje de Vives a París, a mediados de 1519 , certificado por las respectivas correspondencias de Erasmo y Budé. La epistola de Vives (1108) sería la primera de todas; la carta más breve de Erasmo (1104, Quid te felicius) sería la respuesta efectiva del maestro; la más extensa (1111, Subtristem $m e$ ), en cambio, sería una elaboración literaria de la primera respuesta. Esta versión posterior, preparada a la vela de la edición de su nuevo epistolario (las Epistolae ad diversos de agosto de 1521), haría de Vives el destinatario sólo nominal de una nueva pieza de propaganda humanística, en realidad dirigida al público lector; de ahí la poca importancia de si tenía o no anacronismos respecto de la situación de 1519.

1. A fin de que nos resulte claro lo propuesto, hagamos un repaso de los puntos salientes de las tres epistolas:

- En la Ep. 1108, Progresso mihi, cuenta Vives a Erasmo que:

1) Durante un viaje en que aquél acompañaba al cardenal Croy, llegaron hasta la frontera con Francia. La proximidad de París llenó a Vives de deseos de visitar a sus viejos compañeros y el cardenal le permitió cumplir su antojo. Sin embargo, como acababa de 
escribir su librito In pseudodialecticos ("quod eo tempore adversos pseudodialecticos scripssem"; líns. 7-8), dirigido expresamente contra los sofistas parisienses, tuvo miedo de una recepción hostil. Recelo infundado, porque sus amigos lo acogieron espléndidamente, y hasta le llevaban gentes nuevas. Por las dudas, él eludía tocar el tema del libelo; pero Juan Fort, el destinatario, lo menciono, entre risas, y provocó una carcajada generaī (î́ns. $\mathbf{i}-\mathbf{2} 3 \hat{3}$ ).

2) Pudo constatar que los profesores han cambiado mucho, que hasta los estudiantes españoles empiezan a inclinarse por las letras y ofrece una lista de los más destacados (23-42). ¡Si Erasmo viera cuánto y cuántos honraron y obsequiaron a Vives! (42-49). Comía con ellos "frequenter et suauiter",

3) y a la tercer palabra salía el nombre del holandés. ¡Si el discípulo pudiera elogiar a su maestro como quien habla de otra persona! Pero debe callar lo que decían de su edición de Jerónimo, por la que el texto ha sido restituido; de su Nuevo Testamento, vuelto a su primera integridad; de sus Paráfrasis, por gracia de las cuales el texto de San Pablo aparece más claro; de los Adagios, de la Copia y de otras obras profanas; de la Moria, que a todos hace reír sin ofender, a pesar de haber en ella cierta mayor dureza contra los teólogos. 1Oh rústico de Vives, que no puede alabar a su maestro! Pero un día, desobedeciéndolo, lo hará cumplidamente (50-63). Si viera cuántos de los comensales admiran a Erasmo, ofrecen su casa y le ruegan que vaya. De tiempo acá, si un teólogo propone una cuestión tejida con telarañas suiséticas, los espectadores se quejan; si un filósofo plantea enigmas que necesitan de un traductor etrusco - a diferencia ahora de antes-, ese tal es recibido con silbos y tumultos. No duda Vives que estas noticias lo alegrarán (64-83).

4) Pasando de las diversiones a cosas serias, asegura que el fruto máximo de su viaje consistió en que pudo ver a Budé y hablarle; éste, que ya desde entonces era de Erasmo, ahora es suyo o, mejor, común ("quod Budaeum iam olim tuum, nunc meum, imo vero nostrum, videre mihi et alloqui contigerit"; lins. 87-88). ¿Qué hombre, así hablemos de su ingenio, de su erudición, costumbres o fortuna! Grandes elogios a su claridad y elocuencia, a sus libros (los cinco Del as y sus Anotaciones a las Pandectas hicieron avergonzarse a todos los eruditos de Italia con el conocimiento de autores que demuestran) y a su temple moral (líns. 84-126). Erasmo ama a Budé y Budé a Erasmo. Cada uno considera al otro el mejor de los sabios de los Alpes arriba. Pero porque el francés, jugando, trató al holandés un poco más amargamente de lo que convenía, hubo mucha discusión, tanto por causa de ellos mismos como por el asunto discutido: ambos se escribian largas cartas que no siempre iban a ser de elogio pues, según dice Cicerón, jcómo puede darse elocuencia sin un poco de antagonismo entre las partes! Aqué- 
lla habría languidecido si sólo se hubieran cursado alabanzas (líns. 127-150). En medio de estas discusiones, la apología de Erasmo con. tra Lefevre encendió más los ánimos de Budé. Pero lo que para los extraños eran dentelladas, entre estos viejos amigos eran simples asperezas. De lo que no duda Erasmo, y Vives también lo garan. tiza, es del buen ánimo de Budé hacia aquél (líns. 151-175).

Si su maestro viera las cartas que Budé mostró a Vives, escritas por furias, no por hombres, con ánimo de meter discordia y suspi. cacias entre ambos. El valenciano dijo lo que pudo para aplacar a Budé, escaldado con tanto veneno; pero era innecesario, dada la gran proclividad del francés hacia los sentimientos amistosos. Yo respondo - dice- de que la concordia entre ambos sea perpetua, para la felicidad y utilidad de las letras y los estudios (líns. 176196). Y baste de eso.

5) Vuelve al tema del viaje: los amigos pensaron que sería gran pecado si Vives interrumpiera sus lecciones durante más de quince días, por lo que decidieron que enseñara cualquier cosa en París. $\mathrm{Y}$ para no ponerse serios, Vives optó por un sueño, dẹ modo que si entre tanta comilona dormitaba, no faltase al decoro. Soñó pues el de Escipión. Despierto ya, preparaba el regreso, que se posponía por nuevas invitaciones y banquetes. La cosa fuera para largo, de no haber recibido una oportunísima carta del cardenal, que requería cuanto antes su presencia. Así que dio a todos en la cara con sus cenas y-digamos- antojitos, y a los cinco días de salido de allá, que era fiesta de la Trinidad, llegó por carro a Brujas y al siguiente le escribe. Salud. "Adiós y adiós mi querido maestro" (líns. 197-212).

- En la carta 1104, Quid te felicius, dice Erasmo:

1) ¿Quién más feliz que tú, eruditísimo Vives, que aun maldiciendo alcanzas gracias, cuando nosotros bendiciendo concitamos odio y envidias? Hemos tratado de abrir las fuentes de la verdadera piedad y religión, de restituir la teología a su primera majestad en vez de dedicarla a argucias, y ciertos monjes se ensañan conmigo como contra quien ha cometido un crimen; tú en cambio encuentras tan agradables a los sofistas, gente, según dicen, irritable (líns. 1-8).

2) Hace tiempo que admiro el candor y la cortesía de la universidad de París, que por tantos años soportó y aún alentó a Fausto; 2a) y al decir Fausto tú sabes a qué me refiero. Con qué petulancia gritaba contra los teólogos. Tampoco era un secreto su tenor de vida. Y esto hacía la academia por alguien que nunca pasó de mediocre (líns. 8-17). 2b) Los próceres de acá, en cambio, no aceptan al Colegio Trilingüe, que gratuitamente favorece los estudios y que da lucimiento no sólo a esta universidad, sino a 
todas las tierras del príncipe. No toleran a maestros de costumbres puras y de doctrina superior a la de Fausto. París, en el género de estudios que se propuso, siempre fue la primera; no obstante, se alegra si cualquiera puede traerle algo más pulido y da un lugar a quien desee profesar por paga (líns. 18-25). 2c) Aquí, Guillermo Nessen quiso profesar gratis la Geografía de Mela y se opusieron como si se hubiera propuesto incendiar la ciudad. Hace pocos años, esta universidad languidecía; ahora, dedicada a buenos estudios, ha mejorado su fama. Pero ello pesa a dos o tres que, si no ceden, serán derrocados por el peso de mejores estudios; especialmente si tú entras al combate (líns. 26-34).

3) De Budé, si nada nuevo me dices, me alegré de tus alabanzas a mi amigo; él nunca se alienará de Erasmo aun si le escribe las más atroces invectivas (líns. 35-39).

4) Tienes esta lacónica epístola. Así suelo responder a las cenas de Lúculo con convites de Diógenes. Pero no lo achaques al ánimo sino a mis ocupaciones. Adiós, Lovaina. Año 1519 (líns. 40-42).

- Por último, en la carta Subtristem me, 1111, dice Erasmo:

1) Estaba triste y decaído, cuando la lectura de tu carta me hizo carcajear: de tal modo pintaste tu viaje que casi lo veía con los ojos. Tu buena estrella hizo que tú, tránsfuga de los sofistas, no fueras lapidado en aquella como su fortaleza (líns. I-9). Me alegro por tus éxitos y

2) por ver que todavía existe la antigua tradición de la universidad de París. ¿Quién no puede esperar que un día la Sorbona se abrirá a la nueva teología? Me alegro por el regreso de las musas a las escuelas públicas. Ojalá y aquellas discusiones de bárbaros no impidan el desarrollo de las artes necesarias. Pero tampoco se trata de estudiar las puras letras, como en Italia, donde, a manera de paganos, se creen absolutamente doctos con sólo nombrar a Júpiter y a Baco. Estas disciplinas son buenas como condimento de otras más graves (líns. 10-22). 2b) Mucho me sorprende que mientras casi todas las universidades del mundo han llegado a una cierta moderación, sólo en Lovaina exista tan pertinaz oposición a mejares letras; más aún cuando aquí nunca floreció demasiado el género sofístico. El obispo Fisher me contaba que mucho se ha abandonado la sofistería en Cambridge. En Oxford, la autoridad regia y la del cardenal sirvió para doblegar la dictadura de ciertos monjes. Qué decir de Italia, donde estos estudios brillaron siempre, excepto en medicina y jurisprudencia. La fama de Alcalá procede de su conjunción de las lenguas con las buenas letras. En Alemania hay tantas universidades como ciudades, y no hay salario, por alto que sea, que no paguen a los profesores de lenguas. Sólo Cólonia no aprecia los estudios sosegados, quizás por el predominio de fran- 
ciscanos y dominicanos. $\mathrm{Y}$ sin embargo, dejan enseñar a cualquiera (líns. 23-46). 2c) En Lovaina, qué motines tuvieron que aplacar los próceres para impedir que alguien enseñe, aunque gratis. De qué modo conspiraron contra algo de tanto provecho para la academia y para toda la región. Sacaron una vieja ley, intervino la más alta autoridad universitaria, fue llevado el caso al tribunal real, llamaron a funcionarios civiles y aún a la fuerza pública (lictores). No sólo fuiste testigo de este tumulto, sino de algún modo participaste. No toman en cuenta que mejores letras ayudarían a la universidad ni les importa la rectitud de los profesores y la honestidad de las doctrinas. 2a) En París se dejaba a Fausto enseñar a cualquier poeta, sin excluir las Nenias priapeas, y 2c) Aquí no dejan a Nessen enseñar la Geografía de Mela. 2b) Nosotros (en Lovaina) hemos atacado de tal modo al colegio Trilingüe - del que se seguiría no menor utilidad para los estudiosos que para todos los dominios cesáreos- que dudo sea posible hacerlo con mayor obstinación. Empero, no creo que en otra parte se estudien las letras mejor que aquí (líns. 42-70).

3) En lo que dices del aprecio por mis libros, aunque reconozco el buen sentir de los franceses, temo que tu juicio lo haya dictado el entusiasmo por mi persona. Galia me llama, mas no sé qué me ata a Lovaina, el deseo de no abandonar la arena; pero la lucha no tiene fin (líns. 71-79).

4) A Budé, al que tanto alabas, yo lo defiendo entre los alemanes como al primero y único, y les digo que en esto Galia nos gana. Aquellas escaramuzas ya las tengo olvidadas, y a Lefevre lo tengo por varón integérrimo y doctísimo (líns. 80-89).

5) Al cardenal Croy, que estimo por tantas razones, lo quiero también por haberte regresado con nosotros, librándote del riesgo de una congestión. Adiós doctísimo Luis y que cuanto antes te veamos por acá, jovial y risueño (líns. 90-94).

Del cotejo de las tres epístolas resulta inequívoco que las dos de Erasmo responden a la misma carta del valenciano (1108), y a ninguna otra. Al mismo tiempo, que la misiva aquí presentada en tercer término (1111) fue escrita por Erasmo teniendo a la vista tanto el manuscrito de la carta de Vives, como el de la reseñada en segundo lugar (1104)), al grado que podemos decir que una no es sino reelaboración de la otra. Véase, si no, la correspondencia de los cinco apartados en que dividí la carta de Vives, con otros tantos lugares en una $u$ otra de Erasmo, salvo que en la primera quedaron algunos puntos sin responder, de lo que Erasmo se excusa. Al mismo tiempo, el asunto número dos es glosado mediante tres tópicos que aparecen, con distinto orden, en ambas respuestas. Ningún asunto nuevo, salvo que la perspectiva temporal se ha desplazado: el negocio Budé ya no molesta a Erasmo tanto en la 
segunda carta, y el de Nessen ha llegado al punto de desencadenar motines.

Esta constatación textual hace innecesaria la hipótesis de Allen de un doble viaje a París, en 1519 y 1520; pero por sí sola no desvanece las dificultades.

2. Admitido que las tres epistolas tratan de un solo viaje de Vives a París, queda el problema de que las dos respuestas de Erasmo, aun aludiendo al mismo viaje, remiten a sucesos próximos a 1520: ¿En qué fecha tuvo lugar el desplazamiento en cuestión? Queda fuera de duda que Vives estuvo en París a mediados de 1519. La carta de Budé a Erasmo del 10 de junio de dicho año (ep. 987) fue entregada por aquél a Vives para que la llevara a su maestro, según Budé mismo lo declara el 30 de junio (ep. 992). En ambas habla a Erasmo de la buena impresión que le causó aquel joven discípulo del roterdamés, al que vio en dos ocasiones. Esta buena impresión es confirmada en la práctica por el hecho de que, entre agosto de 1519 y mayo de 1520, el humanista francés escribió cuando menos cinco largúsimas misivas a su nuevo amigo español, llenas de recomendaciones y de pesados alegatos en broma por medio de los cuales Budé defiende el actual silencio de su pluma, frente a las repetidas instancias de Vives para que no interrumpa la producción de sus escritos filosóficos. $\mathrm{Y}$ digo repetidas instancias, porque el incansable valenciano escribe dos o tres epístolas por una que Budé responde. En la primera de las del francés (19 de agosto de 1519), éste menciona expresamente las recientes conversaciones tenidas con el español. ${ }^{26}$ No obstante sus apremios, Vives, que toma el papel de discipulo, es un corresponsal idóneo para el doctoral Budé, que puede darle todos los consejos que se le ocurran y abundar en manifestaciones de afecto, a diferencia del quisquilloso de Erasmo.

Según Allen, la carta de Vives a Erasmo se escribió el 4 de junio de 1520, al día siguiente del de la Trinidad. ¿Es concebible que Vives hablara por estas fechas de Budé como de alguien a quien acaba de conocer, alguien que por fin le es "propio", cuando ya lo era de Erasmo desde tiempo atrás; pero que en adelante podrán compartir su amistad? ¿No habían bastado la doble entrevista de 1519, todo un año de nutrida correspondencia y los saludos que se enviaban por medio de Erasmo?

Vives dijo que salió de París el día de la Trinidad. Budé mismo declara haberle entregado una epístola para Erasmo, la del 10 de junio

26 No hay edición moderna del epistolario de Budé. Las cinco epístolas aludidas aparecieron en las Epistolae (priores) G. Budaei... Paris, Bade, 1520 (agosto). La única traducción de ellas aparece en $\mathrm{J}$. Delgado (n. 21), pero llena de incorrecciones aun en la datación. Añádase, de la misma época, una de las editadas por Goldast en su Philologicarum Epistolarum centuria una, Francfort, E. Emmelius, 1610, pp. 217-223. 
de 1519. Ese día - aunque Budé no lo menciona- era la fiesta de la Santísima Trinidad. Consecuentemente, a menos que tengamos que aceptar que también un año después abandonaba la ciudad del Sena el día de la misma fiesta, la carta de Vives debe fecharse hacia el 16 de junio de 1519.

3. Aunque el valenciano escribe en Brujas su epístola, en realidad vive en Lovaina, de donde el cardenal, que estudia en esta ciudad, lo mandó llamar. El paso por Brujas, consecuentemente, debió ser breve, so pena de contravenir las órdenes de su patrón. Y como Erasmo a la sazón también vivía en Lovaina, nada impide que el mismo Vives haya sido correo de la misiva de Budé, junto con la suya propia. De cualquier modo, ¿para qué escribir lo que podía decir verbalmente? Porque no existiendo el motivo de la distancia, tampoco hay nada en el texto que requiera valerse de la expresión escrita, ni —bien visto- un asunto particular que exigiera de Erasmo una contestación de tipo epistolar; menos aún, dos. ¿Por qué, entonces?

Si planteamos que se trata de un juego literario-epistolar entre dos humanistas, ejercicio al que eran tan aficionados dadas sus manías ciceronizantes, nuestras tres cartas quedan explicadas. Cuando un humanista recibía una epístola no dictada por la necesidad o por otro motivo preciso, v. gr., una confidencia, en realidad recibía un envite: alguien, conocido o no, ofrecía al destinatario una muestra de su talento literario real o pretendido, mediante el desarrollo de un tópico cualquiera. EI segundo juzgaba, en el caso de un desconocido, si respondía o no; en el caso de un amigo, no contestar era descortesía.

Conocido o no el autor, la carta recibida daba la pauta para la respuesta. En primer lugar, la lengua: a una carta griega de Budé, Erasmo no podía contestar en otro idioma. Cuando Vergara escribió a su paisano el teólogo Zúñiga en latín y el otro respondió en castellano, el caso circuló, no sin reprobación, entre varios humanistas. ${ }^{27}$

Más importante aún, el respondente no podía permitir que su ingenio y talento literario parecieran menores que los evidenciados en la otra carta. Vives alude precisamente a este asunto cuando habla de los motivos que enredaron la relación epistolar entre Budé y Erasmo: sin cierto contraste que estimule el ánimo del contrario, una correspondencia pasaría a convertirse en repertorio de alabanzas y aquélla se transformaría en algo aburrido y, pecado de pecados, inelocuente (líns. 146-149).

De hecho, uno de los ejercicios pedagógicos centrales del humanismo consistía en la lectura, audición o composición de un par de oraciones mentación que no debía ser de tipo silogístico, sino apegarse a las reglas 27 Cfr. Allen, 1277. 
de modo que en cada una de ellas se argumentara lo contrario, argude la elocuencia. Así vemos que, como en la oración pretendidamente de Quintiliano Paries palmatum había únicamente el alegato por el que en un crimen supuesto se defendía al ciego contra su madrastra, Tomás Moro instó a Vives a que escribiera la defensa de la madrastra, a fin de yuxtaponer el peso de los argumentos de ambas partes. ${ }^{28}$ Otro tanto valía para las epístolas como género literario: el punto y el contrapunto debían aparecer tanto en el interior de cada epístola como entre la carta enviada y la contestación; pero la regla de arte debía disimularse, y era esta "naturalidad" artística la que determinaba el mérito. ${ }^{29}$

Desde semejante enfoque, la epístola de Vives es clara: 1) exordio: llega a París, con permiso del cardenal; todo son aclamaciones y banquetes; 2) constata, entre copa y charla, un cambio de actitud en la universidad hacia la teología y el estudio de las artes (los temas centrales del erasmismo), para, en ese marco, contar los elogios que se tributan a Erasmo en París, 3) asunto que le da pie para un elogio del maestro y sus escritos, encomio que 4) contrapondrá amigablemente al elogio de la figura y obras de Budé, el talento rival. A continuación, examina los puntos de convergencia entre ellos y lo natural que resulta, por lo mismo, su amistad; sin embargo, por causas subjetivas y objetivas, las cuales expone, actualmente existen riñas entre ellos. Entonces plantea la falta de fundamento de éstas, y repropone una amistad que, al decir de Vives, no ha sido atacada en sus cimientos. Por último, y para concluir en toda forma, 5) Vives vuelve al festivo relato parisiense, que se interrumpe por obra de quien lo había posibilitado: el cardenal.

Si nos atenemos a lo que Erasmo menciona del progreso del caso Nessen, es claro que aquél no contestó inmediatamente después a su discípulo; retardo que él, conociendo su temperamento aprensivo, no se cansaría de recordar al preceptor, reclamando su respuesta. Arrancada a la fuerza o no realizada con demasiada gana, en ella el holandés 1) felicita al viajero por sus éxitos en París, que pone en contraste con los ataques de que él es objeto; 2) el cambio que Vives dice percibir en aquella academia, permite al corresponsal lanzar una invectiva contra la tozudez de las autoridades universitarias de Lovaina: compara la libertad que París concedía al inmoral de Fausto Andrelini para exponer a los poetas más licenciosos, con la negativa lovaniense de permitir al morigerado Nessen la enseñanza de algo tan sano como la geografía de Mela. Llegado al punto de la contraposición Erasmo-Budé (3 y 4), el

28 Declamationes duae prior M. Fabii Quintiliani pro caeco contra nouercam. Posterior Ioannis Lodouici Viuis Valentini pro nouerca Martinum Alostensem Anno. M.D.XXIII. Mense Februario.

20 Cfr. los prólogos y epistolas preliminares a las Declamaciones Silanas de Vives. 
tema le resulta tan irritante que se limita a declarar su amistad con el francés, no sin mandarle una pulla, y 5) corta por lo sano la carta excusándose de ofrecer una contestación diogeniana a la luculenta epístola de Vives.

En 1521, llegado Erasmo al punto de editar su nueva colección de epístolas, y en un momento en que sus relaciones con Budé eran menos tensas que dos años atrás, ${ }^{30}$ no se resistiría a publicar una carta tan elogiosa para su persona como la escrita por Vives. Sin embargo, aunque la respuesta que Erasmo escribiera a su discípulo le había dado excelente ocasión de atacar a sus enemigos de Lovaina, el profesor holandés encontraría su contestación un tanto contrahecha: demasiado diogeniana para una carta tan luculenta (Ep. 1104, final). Entonces, con el texto del discípulo y el de la respuesta original a la mano, Erasmo redactaría una nueva epístola que "contestara" la del valenciano con un poco más de elegancia y que correspondiera punto por punto a los asuntos tratados por Vives. En esta segunda versión, en el apartado (2), el maestro nos ofrece una visión más tardía de los mismos sucesos, que ahora describe desde la perspectiva de los hechos consumados. Tanto así, que deja escapar el comentario de que el español no sólo fue testigo sino parte (Ep. 1111, líns. 45-55) de aquello que, precisamente, le está relatando. Años después (1529), lejos de Lovaina y del marco de las antiguas peleas, el reiterativo Erasmo dejaría pasar a la imprenta el borrador de la primitiva redacción, como si se tratara de otra de sus cartas, no sin asignarle el 1519 como fecha de composición.

\section{IV}

Gracias a estas dilatadas consideraciones entiendo que puede asignarse la fecha de hacia 16 de junio de 1519 para la carta de Vives Progresso mihi (1108); para la epístola de Erasmo Quid te felicius (1104), cualquier día de la segunta mitad del mismo año, posiblemente antes de noviembre, mes en que los disturbios del asunto Nessen estallan, y de los que aún no hay mención. Por último, teniendo la epístola Subtristem me (1111) todos los visos de una reelaboración de la anterior con miras a la imprenta, su data sería próxima a la de la preparación del siguiente repertorio epistolar erasmiano, aparecido el 31 de agosto de 1521; así que podemos darle el segundo trimestre del mismo año. Es cierto que el cardenal Croy muere en enero de 1521, pero Erasmo "responde"

30 Entre 1519 y agosto de 1521 la relación entre estos humanistas pasa de la franca irritación a un modus vivendi epistolar. $C f r$. la secuencia de estas relaciones en $M$. de la Garanderie, La correspondance d'Erasme et de Guillaume Budé, París, Vrin, 1967. 
a una epístola en que aquél juega un papel como vivo, y tocar allí el asunto de su muerte, la volvería extemporánea e "incontestable". Con la explicación aquí propuesta para el discutido "triángulo" epistolar, también espero haber salvado de una manera más consistente los principales problemas que el embrollo aparejaba. Al mismo tiempo, creo haber hecho hincapié en dos aspectos del epistolario erasmiano no siempre muy tenidos en cuenta a la hora de su lectura: en primer lugar, el "ideológico", por lo que puse de manifiesto la conexión de aquellas cartas con la polémica desatada entonces entre escolásticos y humanistas, y el papel que estas colecciones jugaron como armas de combate y propaganda. En segundo lugar, insistí en el lado formal de todas estas cartas de letrados, y señalé que buen número de ellas es explicaba si teníamos en cuenta su carácter de ejercicios de "buena prosa". Manifestaciones de un género literario, tanto o más que simple archivo de documentos históricos, en ciertos casos las exigencias de estilo (y de propaganda) podían dar lugar a retoques mayores y menores del documento original, por lo que debemos en todo caso tratarlos con pinzas; más aún por tratarse específicamente de polémicas.

Por último, el haber podido datar con suficiente seguridad la epístola de Vives en 1519, deja fuera de discusión el problema de si In pseudo. dialecticos - y demás obrillas y epistolas editadas junto con él en Lovaina, sin año, con el título de Opuscula varia - se publicó en 1519 o un año después. La tesis de Allen - que aquí nos negamos a admitirdel viaje a París y carta en 1520, obligaría a recorrer la fecha de este libro en un año, no sin dificultades insalvables al poner en colación dicha data con otras noticias relativas a la vida del humanista valenciano. En cambio, admitida la certeza de 1519 como el año de la carta de Vives, In pseudodialecticos, escrito eo tempore (Ep. 1108, lín. 708), corresponde al mismo año, con lo que se supera todo obstáculo para admitir que los mismos Opuscula varia aparecerían entre abril y mayo del propio 1519, en donde encontramos tres dedicatorias 'fechadas en aquel abril.

La misma relación epistolar de Vives con Budé resulta más inteligible si la carta del español a Erasmo aparece como prólogo a dicha correspondencia y no como un inexplicable parche después de un nutrido año de contacto epistolar.

Alguna ganancia trajo, espero, tan dilatada reconsideración. 